\title{
A Escola Austríaca no pensamento de Donald Stewart Jr.
}

\author{
Lucas Berlanza Corrêa ${ }^{I}$ (1) 0000-0003-2429-021X \\ Instituto Liberal Rio de Janeiro, Rio de Janeiro, RJ, Brasil
}

Resumo: O presente artigo busca sintetizar a influência das ideias e matrizes da Escola Austríaca de Economia sobre o pensamento do empresário e ativista brasileiro Donald Stewart Jr., mostrando o significado de sua atuação para difundir essa escola de pensamento no país. Partindo de uma breve reflexão sobre sua posição histórica como introdutor de uma literatura específica e como fundador do Instituto Liberal, em 1983, esse artigo tentará conectar esse esforço à atual popularidade dos autores austríacos no país, mostrando como o empresário e a instituição por ele fundada foram determinantes para isso. Além disso, com base em sua obra O que é o liberalismo, estudaremos as ideias de Stewart, e como a EA poderia colaborar para resolver os problemas do Brasil.

Palavras-chave: Donald Stewart Jr., Escola Austríaca, liberalismo brasileiro.

\footnotetext{
${ }^{\text {I}}$ Formado em Comunicação Social/Jornalismo pela UFRJ. Colunista do Instituto Liberal desde 2014 e Diretor-Presidente da mesma instituição desde 2018. Autor dos livros “Guia Bibliográfico da Nova Direita: 39 livros para compreender o fenômeno brasileiro" - mencionado por Antonio Paim na obra "História do Liberalismo Brasileiro" como um dos destaques do liberalismo contemporâneo - e "Lacerda: A Virtude da Polêmica". Colaborador como articulista em diferentes coletâneas. E-mail: lucasberlanza@yahoo.com.br.
} 


\title{
The Austrian School in the thinking of Donald Stewart Jr.
}

\begin{abstract}
This article aims to synthesize the influence of the ideas and matrixes of the Austrian School of Economics in the thinking of Brazilian businessman and activist Donald Stewart Jr., showing the meaning of his performance spreading this school of thought in Brazil. Starting from a brief reflection on his historical position as an introducer of specific literature and as the founder of Instituto Liberal in 1983, this work will try to connect this effort to the current popularity of Austrian authors in the country, showing how the entrepreneur and the institution he founded were decisive for this. Besides, we will study Stewart's views, especially from his work What is Liberalism, about how the Austrian School could contribute to solving the problems of Brazil.
\end{abstract}

Keywords: Donald Stewart Jr., Austrian School, Brazilian liberalism.

\section{La Escuela Austríaca en el pensamiento de Donald Stewart Jr.}

Resumen: El presente artículo se destina a sintetizar la influencia de las ideas y matrices de la Escuela Austríaca de Economía en el pensamiento del empresario y activista brasileño Donald Stewart Jr., ofrece un panorama del significado de su actuación al difundir esa línea de pensamiento en Brasil. Partiendo de un breve abordaje sobre su posición histórica como introductor de una literatura específica y como fundador del Instituto Liberal, en 1983, el trabajo trata de conectar este esfuerzo a la actual popularidad de los autores austríacos en el país, mostrando como el empresario, y la institución creada por é, fueron determinantes para esto. Además, exponemos las visiones de Stewart, especialmente a partir de su obra O Que é o Liberalismo (Qué es el Liberalismo), acerca de la contribución que la Escuela Austríaca podría contribuir para resolver los problemas de Brasil.

Palabras clave: Donald Stewart Jr., Escola Austríaca, Liberalismo brasileño. 


\section{Introdução}

O Brasil apresenta uma tradição liberal bastante antiga, entendendo-se aqui o conceito de liberalismo a partir das bases institucionais e teóricas sintetizadas por um dos principais historiadores de ideias brasileiros, Antonio Paim: "o estabelecimento da liberdade religiosa (liberdade de consciência) e da liberdade de imprensa, bem como os parâmetros fundamentais da liberdade individual" (PAIM, 2018, p. 36), pretensões que se materializaram, especialmente entre os séculos XVIII e XIX, considerando-se as limitações vigentes, sob a forma do constitucionalismo e dos sistemas representativos.

No entanto, a tradição liberal do país, que participa de sua construção política pósindependência, realizada na década de 1820, tem tido sempre que se defrontar com outra tradição ainda mais longeva, identificada por diversos cientistas sociais e analistas da realidade brasileira: a de um patrimonialismo persistente que às vezes assume facetas modernizantes, sem perder a sua característica essencial. A doutrina do liberalismo econômico propriamente dita, fundamentada nas ideias de Adam Smith (1723-1790), somente começaria a fazer frente às teses predominantes do mercantilismo no século XIX, quando, por exemplo, o publicista, jurista e político baiano José da Silva Lisboa, o Visconde de Cairu (1756-1835), difundiu suas obras para o público brasileiro.

Desde antes disso, o Brasil sofria a influência marcante da tradição pombalina. De acordo com Antonio Paim, a decisão de Sebastião de Carvalho e Melo (1699-1782), o Marquês de Pombal, de aderir ao mercantilismo, alheio às teorias econômicas liberais, marcadamente de linha britânica, "trouxe consequências perversas para nossa história, porquanto, admitindo a riqueza em mãos do Estado, eximiu-se de criticar a tradição precedente que combatia a riqueza em geral e o lucro" (PAIM, 2018, p. 34). Graças a isso, embora o pombalismo inaugurasse um novo quadro na realidade política e econômica das terras lusitanas, "a admissão da posse de riquezas em mãos do Estado passou a coexistir com a velha tradição, crescentemente dirigida contra o empresariado privado" (PAIM, 2018, p. 34).

Incrementando esse cenário:

Pombal também deu à burocracia estatal uma grande supremacia em relação aos outros grupos sociais. O Estado português, que era tipicamente um Estado Patrimonial, isto é, parte do Patrimônio do Príncipe e não um órgão a serviço da sociedade, passou a atribuirse a função de promover a modernização (predominantemente econômica) como algo que deveria beneficiar diretamente aquela burocracia. (PAIM, 2018, p. 34)

O enraizamento dessa poderosa tradição patrimonialista modernizante foi tão significativo na cultura política brasileira, tal como, além de Paim, também apontam autores como Ricardo Vélez Rodríguez e Simon Schwartzmann, inspirados nas análises do conceito de patrimonialismo constante das obras de sociólogos como Max Weber (1864-1920) e Karl Wittfogel (1896-1988), que suas manifestações persistiram ao longo da História, quer do Império, quer da República no país. A ascensão de ideologias como o positivismo, o castilhismo ou as diversas variantes da social democracia e do socialismo que irromperam ao longo do ciclo republicano, após 
o golpe que depôs a monarquia em 1889, apenas reforçaram essa dimensão estrutural tão marcante, de que o Brasil jamais logrou êxito em se desvencilhar.

A experiência de construção do Estado brasileiro, efetivada sob a égide do grupo dos chamados liberais moderados que se saíram vitoriosos após as turbulências do período Regencial, organizados em torno da Constituição de 1824, conseguiu uma peculiar estabilidade institucional, que não sobreviveu à ação militar que levou à presidência provisória de Deodoro da Fonseca (1827-1892) e à posterior Constituinte de 1891. O liberalismo republicano, obrigado a conviver com as influências do positivismo e do jacobinismo nacionalista de certas alas militares, bem como com manifestações autoritárias como as do florianismo, se descuidou da teoria do sistema representativo por interesses, alicerçada, no Império, na obra do teórico do período joanino Silvestre Pinheiro Ferreira (1769-1746).

Em parte em decorrência desse descuido, o liberalismo republicano sofreu um eclipse robusto com a ascensão de Getúlio Vargas (1882-1954). Paim define os cinquenta anos que se sucedem à sua tomada de poder, com a Revolução de 30, como o predomínio "daquelas vertentes do autoritarismo doutrinário que despontaram na República Velha" (PAIM, 2018, p. 209). Em sua visão, depois da queda da ditadura do Estado Novo, em 1945, o liberalismo brasileiro se distanciou "do contato com as fontes externas, que sempre constitui preocupação das figuras proeminentes da facção liberal" (PAIM, 2018, p. 211). Existia por parte de algumas figuras públicas certa admiração pela economia social de mercado ou ordoliberalismo, especialmente em virtude de seu sucesso para reerguer a Alemanha, mas nenhuma vinculação direta ao pensamento da Escola Austríaca.

Ao longo de todo esse período, basicamente um único autor se singulariza por ceder a influências relevantes dessa escola: o economista Eugênio Gudin (1886-1986), personalidade muito representativa dos grandes debates intelectuais da metade do século XX, notabilizada por seu enfrentamento teórico ao industrialismo desenvolvimentista de Roberto Simonsen (1889-1948) - este último tendo sido vencedor prático da contenda na década de 40. Gudin chegou a integrar a icônica Sociedade Mont Pèlerin, fundada, em 1947, pelo ativismo do mais laureado militante dessa corrente de pensamento econômico liberal, Friedrich Hayek (18991992). Ele era simpatizante da União Democrática Nacional, o partido que reunia as principais figuras liberais da época, e entusiasta da liderança de Carlos Lacerda (1914-1977), tribuno mais expressivo da sigla. Gudin também chegou a ser ministro da Fazenda durante o breve período do governo de Café Filho (1899-1970), que assumiu o poder logo após o suicídio do presidente Vargas.

Apesar de seu impacto nas esferas intelectuais, Eugênio Gudin não conseguiu ser decisivo quanto à consolidação de uma linha de políticas orientadas para o liberalismo econômico, sendo Café Filho logo sucedido pelo desenvolvimentismo de Juscelino Kubitschek (1902-1976). Apesar de suas recorrentes citações a Hayek e a seu mestre, Ludwig von Mises (1881-1973), Gudin não pôde criar um movimento intelectual expressivo que modificasse os rumos triunfantes do patrimonialismo modernizador. Conseguiu, entretanto, influenciar sucessores, em especial Otávio Gouveia de Bulhões (1906-1990) e Roberto Campos (1917-2001), este último convertido, após o regime militar, entre as décadas de 80 e 2000, em um militante destacado 
das privatizações, do combate à inflação e de todo o receituário liberal econômico, mas que apenas nesse período final de sua biografia se converteu totalmente às teses de Hayek.

Entre o golpe de 1964 e o regime militar - em que, aliás, do ponto de vista político, o próprio Eugênio Gudin chegou a apoiar o autoritarismo de medidas como o Ato Institucional Número 2 - e os governos da Nova República, em que foram adotadas estratégias intervencionistas como o Plano Cruzado do governo de José Sarney, diferentes facetas do patrimonialismo modernizante e da aposta no Estado como ativo elemento condutor da economia continuaram prevalecentes. Os principais economistas liberais, como Mário Henrique Simonsen (19351997), já de influência reduzida no rumo dos acontecimentos, estavam predominantemente vinculados às concepções monetaristas de Milton Friedman (1912-2006) em vez de às ideias dos austríacos.

A tradição liberal brasileira, em suma, nasce com o liberalismo político, em especial diante do problema do constitucionalismo e da representação. A seu lado, no século XIX, ingressa à discussão o liberalismo econômico, que encontra ainda mais dificuldades ao se defrontar incessantemente com a cultura política patrimonialista, reforçada por sua faceta modernizante, ainda que em poucos períodos tenha deixado de ter os seus defensores. Faltou, entretanto, até a década de 80 , um centro organizado de pensamento cuja missão fosse difundir, em primeiro lugar, algumas das principais obras do liberalismo, a começar pela bibliografia estrangeira que não ocupava posição de preponderância entre os que assim se identificavam no país.

Esse papel coube ao empresário de origem familiar canadense Donald Stewart Jr. (19311999), que, em 1983, decidiu criar uma organização voltada à produção e divulgação de ideias e autores inseridos no contexto do liberalismo: o Instituto Liberal. Desde sua origem, o Instituto Liberal funcionou como um núcleo capaz de reunir autores de tendências distintas, como o próprio Roberto Campos e o jovem pensador José Guilherme Merquior (1941-1991), entusiasta do que chamava de social liberalismo. Para Paim, cabe à instituição criada por Stewart, "pelo menos em parte, a intensa mobilização que o empresariado brasileiro passou a desenvolver nos últimos anos em prol da abertura econômica, da privatização e da extinção dos monopólios estatais" (PAIM, 2018, p. 347). Ainda segundo aquele autor, o esforço de Stewart foi decisivo no ciclo de mobilizações para tentar efetivar "a substituição do tradicional patrimonialismo brasileiro por meio do qual o Estado domina a economia" (PAIM, 2018, p. 347).

Particularmente, embora o Instituto Liberal, como se vê, não tenha sido criado apenas para isso, serviu também como um espaço de tradução de livros e exposição, para certo público, pela primeira vez, dos autores e pensamentos da Escola Austríaca. O próprio Donald Stewart Jr., tal como Roberto Campos veio a se tornar na reta final de sua vida, se transformou em um franco adepto das teses de Friedrich Hayek. Sem esse trabalho, dificilmente se poderia verificar a ascensão de outras instituições, algumas focadas exclusivamente na Escola Austríaca, como o Instituto Mises Brasil, fundado em 2007, e de uma militância abrangente que adota as figuras de Mises, Hayek ou Murray Rothbard (1926-1995) como suas principais referências.

Dada a importância do trabalho de Donald Stewart Jr. na transformação do cenário intelectual brasileiro, trazendo alicerces indispensáveis para a consolidação de uma linha de pensamento que, se não era completamente inédita, padecia de extrema carência de vulgarização 
e reconhecimento no país, justifica-se o propósito de reconstruir, em primeiro lugar, sua vida e ações para que esse cenário novo se viabilizasse e, em sequência, de que forma as ideias da Escola Austríaca aparecem em seu próprio pensamento acerca das questões gerais da política e da economia e de sua aplicação à realidade brasileira, pensamento esse que está exposto detalhadamente em seu opúsculo O Que é o Liberalismo (1988).

\section{Donald Stewart Jr.: Vida e Obra}

Apesar da grande importância para o momento contemporaneamente vivido pelo liberalismo e pela Escola Austríaca no Brasil, Donald Stewart Jr. foi objeto de apenas um esforço de reconstrução biográfica: o documentário Donald Stewart Jr., produzido por sua filha, Ana Stewart. Antes de ser, como o definiria Paim, "um dos líderes do grupo de empresários que assumiu a responsabilidade de divulgar, junto ao empresariado brasileiro, as ideias do liberalismo econômico, especialmente na versão que lhe deu Ludwig von Mises e F.A. Hayek" (PAIM, 2018, p. 347), Donald já havia construído uma longa trajetória no ramo da engenharia civil e dos negócios.

Ele iniciou sua vida profissional na empresa Ecisa em 1950, na função de estagiário, ascendendo até o ponto em que se tornou diretor-presidente e principal acionista. Um dos sócios da Ecisa em seu início era Hélio Beltrão (1916-1997), que chegou a ser ministro do Planejamento, da Previdência Social e da Desburocratização durante os governos militares, além de presidente da Petrobras, conhecido por sua defesa da redução da intromissão estatal na vida dos cidadãos e da simplificação da máquina pública. Ainda como funcionário, Donald Stewart Jr. participou da construção da capital do Brasil, Brasília, tornando-se gerente da filial da Ecisa durante a obra.

Um detalhe curioso da biografia de Stewart era sua ligação com o samba carioca, tendo tido responsabilidade direta na construção da sede da famosa escola de samba Estação Primeira de Mangueira. Outra paixão do empresário era o hipismo, a que se dedicava de forma amadora.

Na liderança da Ecisa, Stewart comandou a realização de diversas obras importantes, trabalhando para o governo, inclusive fora do Brasil, como no caso da construção de uma grande estrada na Tanzânia. Essa experiência de relacionamento com o setor público, de acordo com o próprio Donald, ajudou a forjar suas prevenções com a dinâmica estatal. $\mathrm{O}$ próprio Donald relata que deliberou não ter mais qualquer envolvimento profissional com governos, transformando o rumo de sua carreira para comandar apenas a construção e gestão de shopping centers.

Além da experiência pessoal, a leitura do livro O Caminho da Servidão (1944) de Hayek estimulou sua conversão plena ao pensamento liberal. A partir dessa fase, ele assumiu o papel histórico que o notabilizou como ativista do liberalismo. Travando contato com intelectuais como José Guilherme Merquior e Og Francisco Leme (1922-2004), Donald Stewart Jr. fundou no Rio de Janeiro o Instituto Liberal em 1983, constituindo-o como uma sociedade sem fins lucrativos, mantida por doações privadas. Era o início de uma longa sequência de palestras, 
discursos, participações em colóquios e iniciativas similares, desvinculadas de qualquer envolvimento partidário, sempre exclusivamente militando pelos princípios do liberalismo.

O Instituto Liberal, em primeiro lugar, tinha o propósito de traduzir livros, porque, como Donald relatou, estava incomodado com a carência de indicações de literatura liberal e libertária nos materiais didáticos das universidades. A Escola Austríaca, sem dúvida, foi a mais beneficiada com esse esforço, até então conhecida por apenas alguns círculos, como o de Eugênio Gudin. O propósito de Donald era similar ao de Hayek ao criar a Sociedade Mont Pèlerin:

No ano de 1947, Hayek organizou e liderou um encontro com 39 estudiosos de 10 países, considerados os principais expoentes internacionais da cultura liberal, no Mont Pèlerin, Alpes suíços. Esse foi o começo da Mont Pèlerin Society, uma organização dedicada a articular os princípios que levariam ao estabelecimento e a preservação de sociedades livres. Após a Segunda Guerra Mundial, a economia planejada, a intervenção estatal e as nacionalizações estavam obtendo grande visibilidade. Vários políticos e intelectuais estavam convencidos de que o progresso seria alcançado pela intervenção do Estado. A Mont Pèlerin Society surgiu com o objetivo de combater essas ideias, julgando-as incompatíveis com a liberdade individual e uma economia de livre mercado. Seu único objetivo é, ainda hoje, o de facilitar a troca de ideias entre acadêmicos e intelectuais notórios que compartilham a mesma opinião, na esperança de fortalecer os princípios e a prática de uma sociedade livre. (XAVIER, 2019, p. 67-68)

Munido do exemplo de Hayek, Stewart criou o Instituto Liberal como uma espécie de Mont Pèlerin brasileira, mas, além de reunir e facilitar a troca de ideias, ele precisava trazer algumas das ideias a um grande público, que as desconhecia, bem como a lideranças de diversos setores da sociedade, do setor acadêmico ao setor político. Assim como Hayek, Stewart acreditava que a transformação da sociedade para rumos mais liberais precisaria começar pela reforma de suas ideias predominantes e, portanto, era esse o campo que precisava ser atacado inicialmente pelos ativistas do liberalismo.

Com seu incentivo, surgiram Institutos Liberais em diferentes estados, reunidos em 1988 para estabelecer uma Declaração de Princípios, que refletia as balizas que todos deveriam defender para que se reconhecessem como aliados, cada um articulando-se com os projetos e iniciativas que lhes parecessem mais adequados. A maioria desses institutos posteriormente desapareceu, mas o Instituto Liberal original permanece em atividade.

Além de publicar pela primeira vez obras de autores da Escola Austríaca de Economia, o Instituto Liberal também divulgou o pensamento de autores como o francês Frédéric Bastiat (1801-1850) e a russo-americana Ayn Rand (1905-1982), entre muitos outros. Também publicou pensadores nacionais, como Alberto Oliva e Ricardo Vélez-Rodríguez. Donald Stewart Jr. faleceu em 1999, aos 68 anos, sem cessar até o fim de sustentar as teses do liberalismo, tanto na dimensão política quanto na dimensão econômica. 


\section{O Conceito de Liberalismo de Donald Stewart Jr. sob a Ótica da Escola Austríaca}

O primeiro aspecto no pensamento de Donald Stewart Jr., a ser considerado para averiguar o impacto dos autores austríacos na sua formação intelectual, é a sua conceituação de liberalismo. Tendo dedicado quase duas décadas de vida a defendê-lo e divulgá-lo entre os brasileiros, importa antes de tudo apreender o seu entendimento acerca desse termo.

Na concepção de Donald, o liberalismo é, ao mesmo tempo, um sistema político, estruturado como um corpo de ideias, e um conjunto de fatos sobre os quais esse sistema se estrutura. Esses fatos seriam empiricamente fundados em leis econômicas que a ciência econômica, uma vez desenvolvida, estaria descortinando, sobretudo a partir do final do século XVIII.

É assim que Donald define o liberalismo como "uma doutrina política que, utilizando ensinamentos da ciência econômica, procura enunciar os meios a serem adotados para que a humanidade, de uma maneira geral, possa elevar o seu padrão de vida" (STEWART JR., 2019, p. 25). Não obstante o instituto por ele fundado tenha sido sempre tolerante e aberto à expressão de perspectivas diferentes do liberalismo, do social-liberalismo de Merquior ao objetivismo de Ayn Rand, a filiação do empresário à Escola Austríaca se revela patente quando ele afirma que, apesar de ser possível, até o início do século XX, "formar uma ideia sobre o ideário liberal a partir do estudo das obras dos grandes mestres do liberalismo clássico e dos diversos autores que os seguiram" (STEWART JR., 2019, p. 25), o pensamento liberal só teria sido efetivamente enunciado, de forma organizada, por Ludwig von Mises no final da década de 20. Esse enunciado, para ele, seria o seguinte:

O liberalismo não é uma doutrina completa e nem um dogma imutável. Pelo contrário, é a aplicação dos ensinamentos da ciência à vida social do homem. Assim como a economia, a sociologia e a filosofia não permaneceram imutáveis desde os dias de David Hume, Adam Smith, David Ricardo, Jeremy Bentham e Whilhelm Humboldt, assim também a doutrina do liberalismo é diferente hoje do que foi à sua época, muito embora seus princípios fundamentais tenham permanecido inalteráveis. Durante muito tempo, ninguém tomou a si a tarefa de apresentar uma exposição concisa do significado essencial dessa doutrina. Isso pode justificar nosso presente esforço em fornecer justamente este trabalho. (MISES, 1987, p. 5)

Precisamente por reconhecer no liberalismo a sua dimensão histórica de doutrina que não é dogmática, não teria expressado ainda a última palavra sobre a humanidade e estaria sujeita a absorver modificações e novas experiências políticas e sociais, Donald admitia a existência de uma diversidade de escolas e interpretações liberais. Entretanto, sua concepção, ao mesmo tempo, é de caráter evolucionista e entende que as formulações mais recentes do pensamento liberal empreenderam enunciados mais abrangentes e explícitos da consistência desse pensamento. $\mathrm{O}$ momento mais marcante dessas enunciações teria sido essa conceituação feita por Mises, o que faz da Escola Austríaca, aos olhos de Stewart, um dos capítulos mais importantes da história do liberalismo, senão o mais. É ela que, na sua avaliação, "explicita a doutrina liberal de forma mais completa e mais consistente” (STEWART JR., 2019, p. 31). 
A diversidade do liberalismo, para ele, não poderia ser usada como pretexto para julgá-lo "uma ideia desarticulada" (STEWART JR., 2019, p. 26), permitindo "que a inegável popularidade do conceito de liberdade, e de seus derivados liberal, libertação, seja usada como um biombo para esconder ideias retrógradas e já superadas, como o mercantilismo e o Estado provedor" (STEWART JR., 1999, p. 13). Em vez disso, a concepção de Stewart é também de apelo científico. Ele não expõe o liberalismo em seu texto como uma ideologia entre outras, mas como um conjunto de princípios fundamentais, "presentes em todos os autores verdadeiramente liberais" (STEWART JR., 2019, p. 26), cujas inspirações são fenômenos empiricamente observáveis e cientificamente constatáveis. Sendo assim, todas as doutrinas erigidas contra o liberalismo, não obstante elas tenham a liberdade de se expressarem e serem enunciadas, em consonância com o que os próprios valores liberais preconizam, estariam, em sua visão, objetivamente equivocadas, porque o liberalismo já as teria desmistificado.

A concepção de Stewart acerca do liberalismo novamente reflete um dos autores mais icônicos da Escola Austríaca, quando ele evoca o trabalho de Friedrich Hayek para diferenciar o pensamento liberal do conservadorismo:

Não se deve confundir liberalismo com conservadorismo. Na realidade, liberais e conservadores só têm em comum a sua oposição ao socialismo. Como prevalece de uma maneira geral a ilusão de que o espectro político seja linear, os liberais ora são colocados à direita dos conservadores, ora mais ao centro. Nada mais equivocado. Na realidade, se quisermos usar uma figura geométrica para ilustrar o espectro político, melhor seria usar o triângulo, onde teríamos, nos seus vértices, socialistas, conservadores e liberais. $\mathrm{O}$ excelente posfácio de Friedrich A. Hayek em seu livro Os fundamentos da liberdade - "Por que não sou um conservador" - é uma convincente explicação de mais esse equívoco. (STEWART JR., 2019, p. 29)

A conceituação de Hayek acerca do conservadorismo e de suas diferenças intransponíveis em relação ao liberalismo já sofreu diversas críticas e contextualizações, a exemplo da tese sustentada por Alex Catharino, autor também brasileiro e que igualmente frequentou os círculos do Instituto Liberal, de que a tradição política conservadora, "tal como se manifestou historicamente no Reino Unido, nos Estados Unidos e no Brasil, deve ser entendida como uma vertente" (XAVIER, 2019, p. 25) da tradição liberal. O mesmo autor proclama que Hayek não compreendeu a diferença entre as vertentes tradicionalistas e reacionárias do chamado conservadorismo continental europeu e o conservadorismo anglo-saxão, que, em essência, seria "uma vertente antiprogressista do liberalismo clássico, que, na defesa das tradições da Civilização Ocidental, compreende que os princípios e as instituições liberais já fazem parte desta" (XAVIER, 2019, p. 26).

Catharino considera como provável fonte dessa falha a filiação hayekiana ao pensamento do sociólogo marxista húngaro Karl Manheim (1893-1947), que, estudando as ideias políticas alemãs, concluiu ser o conservadorismo um conceito ligado diretamente à estrutura de classes daquela sociedade, particularmente "uma reação das classes agrárias feudal-aristocráticas à Revolução Francesa" (XAVIER, 2019, p. 26), atrelando, por consequência, o liberalismo exclusivamente à burguesia ascendente e o socialismo e o marxismo ao proletariado. 
Expressando-se em direção contrária à de Hayek e Manheim, Catharino considera que as formas históricas do dito conservadorismo em nações como Reino Unido e Brasil foram mais próximas "das vertentes moderadas do liberalismo clássico que do tradicionalismo reacionário da Europa continental" (XAVIER, 2019, p. 27). Contudo, a linguagem de Donald Stewart Jr. era a de Hayek, reproduzindo sua visão do conservadorismo como um adversário do liberalismo, o que apenas fortalece a demonstração do quanto a Escola Austríaca era o ingrediente essencial de seu pensamento.

Donald Stewart Jr. não trabalha explicitamente com os conceitos de patrimonialismo ou patrimonialismo modernizante, termos presentes nas obras de cientistas sociais e historiadores das ideias como Antonio Paim e seus discípulos, mas ele enxerga a existência, no Brasil, de um substrato cultural avesso ao liberalismo, com que este forçosamente precisa se defrontar. Ele sintetizava esse substrato simplesmente dizendo que a ideologia dominante no Brasil é o intervencionismo, sustentado pelas mais diversas forças políticas que consideram a necessidade de um Estado excessivamente assistencialista e ativo na dimensão econômica.

O liberalismo, ao contrário,

se insurge contra essa ideologia dominante, contra os que a sustentam. Liberalismo é liberdade política e liberdade econômica; é ausência de privilégios; é igualdade perante a lei; é responsabilidade individual; é cooperação entre estranhos; é competição empresarial; é mudança permanente; é a revolução pacífica que poderá transformar o Brasil no país rico e próspero que inegavelmente pode vir a ser. (STEWART JR., 2019, p. 31)

Havia no pensamento de Stewart a convicção de que o Brasil precisava ser profundamente transformado e de que a chave para essa transformação - verdadeiramente revolucionária, mas sem sangue - estaria na aplicação das receitas cientificamente constatadas do liberalismo. Sua percepção, nesse sentido, afronta as interpretações mais céticas e desesperançadas de que o arcabouço da cultura política brasileira obstaria irremediavelmente a que suas instituições e costumes fossem modificados em seus alicerces, tal como, em alguma medida, autores como Raymundo Faoro (1925-2003) chegaram a temer. O Brasil, na leitura de Donald, pode e deve ser drasticamente alterado pelo receituário liberal, porque o liberalismo é um fato cujas leis e implicações são funcionais em qualquer porção do planeta.

Um dos maiores objetivos do liberalismo é, como qualquer outra doutrina política, encontrar uma forma de garantir as melhores condições de vida a todos os membros da sociedade. Tal como outros autores liberais, Stewart está convencido de que, longe de ser uma forma de pensar elitista e excludente, o liberalismo é o melhor caminho para combater o problema da pobreza e da miséria.

Entre os seus pilares, Stewart situa a liberdade, definida como "ausência de coerção de indivíduos sobre indivíduos" (STEWART JR., 2019, p. 110), o que demonstra que, mais uma vez, na linha do que costumam fazer os economistas austríacos, ele adotava preferencialmente o conceito de liberdade negativa, cuja explicação é marcantemente desenvolvida na obra de Isaiah Berlin (1909-1997). 
Stewart desenvolve a definição, estabelecendo ainda que a liberdade "é a adesão ao princípio de que a ninguém é permitido recorrer à força ou à fraude para obrigar ou induzir alguém a fazer o que não deseja" (STEWART JR., 2019, p. 110). No campo econômico, decorre um sistema liberal, marcado pela economia de mercado, que resguardará o direito à propriedade privada e à livre entrada na disputa de mercado, sem garantia de quaisquer privilégios ou monopólios. A liberdade econômica desejada em uma sociedade liberal será aquela em que ninguém possa ser "obrigado, por coerção ou fraude, a comprar, a vender ou a realizar qualquer contrato" (STEWART JR., 2019, p. 112). Já a liberdade política é entendida em sua obra como, "além da liberdade de expressão, de locomoção, de crença, de reunião" (STEWART JR., 2019, p. 114), a "consciência de que deve haver liberdade para escolher as pessoas que irão exercer as funções de governo e que, portanto, irão deter o comando do aparato de coerção e compulsão" (STEWART JR., 2019, p. 114).

Tal como outra figura relevante da fundação e estruturação intelectual do Instituto Liberal, o diretor acadêmico Og Leme, Donald Stewart Jr. jamais abraçou as concepções do anarcocapitalismo enfatizadas por autores mais tardios da Escola Austríaca, como Murray Rothbard (1926-1995) e Hans-Hermann Hoppe, críticos do sistema democrático. Com efeito, o conceito de liberalismo adotado por Stewart, apesar de ter uma base autenticamente austríaca, não reconheceria as ideias de um libertarianismo anarquista como partes integrantes da própria tradição liberal.

Explicitamente, tal como faziam os liberais clássicos e como fizeram Mises e Hayek, Stewart endossava a "imperiosa necessidade de uma ordem geral, estruturada em normas abstratas de conduta, legitimamente geradas pelos cidadãos e eficazmente aplicadas pelas instituições administradoras da justiça" (STEWART JR., 2019, p. 118), instituições essas que precisam fazer parte de um "Estado organizado, que detenha o monopólio da coerção, e de um governo encarregado de administrar o aparato estatal de compulsão e coerção" (STEWART JR., 2019, p. 118). Esse Estado deve ser mantido por meio de impostos definidos pela Assembleia Legislativa e apresentados da maneira mais simples possível - o que demonstra que Donald também não abraçava o conceito da ética libertária de Hoppe, por exemplo, jamais concluindo que o imposto seria essencialmente uma imoralidade. Sobre esse assunto, Mises foi bastante positivo:

Os anarquistas deixam de perceber o fato inegável de que algumas pessoas são ou muito limitadas intelectualmente ou muito fracas para se ajustar espontaneamente às condições da vida social. Mesmo se admitirmos que todos os adultos sadios sejam dotados da faculdade de compreender as vantagens da cooperação social e de agir consequentemente, ainda assim restaria o problema das crianças, dos velhos e dos loucos. (...) Uma sociedade anarquista estaria à mercê de qualquer indivíduo. A sociedade não pode existir sem que a maioria das pessoas esteja disposta a impedir, pela ameaça ou pela ação violenta, que minorias venham a destruir a ordem social. Este poder é atribuído ao estado ou ao governo. O estado ou o governo é o aparato social de compulsão e coerção. (MISES, 2010, p. 189)

Tal como Mises, Donald Stewart Jr. então considerava o Estado simplesmente necessário. Em consequência do caráter imperativo do Estado, teria de haver impostos, pois, como 
pontuaria Mises, "para manter em funcionamento o aparato social de compulsão e coerção são necessários gastos em trabalho e em mercadorias" (MISES, 2010, p. 837).

O liberalismo de Donald Stewart Jr. é avesso ao intervencionismo de nações como os Estados Unidos em território alheio, defendendo o respeito à autodeterminação dos povos, mas admitindo que os Estados se protejam contra agressões de seus vizinhos quando essa for a única opção. É essencialmente pacifista, julgando a guerra um óbice dramático à "possibilidade de cooperação social e de divisão de trabalho" (STEWART JR., 2019, p. 111). Dentro da tradição de Adam Smith, mas ao mesmo tempo repercutindo o conceito de cooperação social dos austríacos, ele via nesse valor um dos pilares do liberalismo, contrariando os críticos que apontam seu suposto atomismo moral. A cooperação social é ressaltada por Mises em sua obra magna Ação Humana, como se destacará mais adiante. Por isso, e como essa cooperação e esse estado de paz são imprescindíveis para o crescimento das trocas econômicas, o Estado liberal deveria ter como seus principais objetivos "manter um clima de paz e tranquilidade nas suas fronteiras" (STEWART JR., 2019, p. 118) e "usar o aparato de coerção e compulsão para impedir - e eventualmente punir - um cidadão que queira usar de violência ou fraude para atingir seus objetivos" (STEWART JR., 2019, p. 118).

Finalmente, uma das formas de resumir com a maior objetividade possível os elementos do liberalismo que Donald Stewart Jr. considerava primordiais é observar a Declaração de Princípios dos Institutos Liberais de 1988, que gozava de sua inteira concordância. Esses princípios fundamentais são: liberdade, propriedade, ordem, justiça, economia de mercado e democracia. $\mathrm{O}$ verdadeiro liberal deveria sustentar incondicionalmente esses seis elementos norteadores.

Foram apontados anteriormente os conceitos de liberdade, economia de mercado e ordem, tal como os entendia Donald Stewart Jr. Sobre este último, cabe acrescentar que a liberdade de Stewart se materializa nas comunidades políticas liberais, portanto, a partir da conformação de uma liberdade submetida à ordem, isto é, uma liberdade ordenada, ordem essa que, como já visto, não dispensa o recurso a um Estado para existir. Ao lado da ordem, esse Estado também desempenha a função de materializar a justiça, compreendida como "a aplicação eficaz das normas gerais de conduta a casos concretos" (STEWART JR., 2019, p. 136), de forma igual para todos os indivíduos, respeitando-se os direitos e prerrogativas das minorias. É uma ideia comum aos principais autores liberais, de Locke a Hayek. Já a ideia de propriedade é definida como "o direito de o indivíduo dispor livremente de seus bens materiais, de sua capacidade de trabalho, de seu corpo e de sua mente" (STEWART JR., 2019, p. 134), garantia indispensável para o equilíbrio e o desenvolvimento da sociedade.

\section{A Democracia e a Demarquia na Obra de Donald Stewart Jr.}

Resta, ainda dentro dos princípios fundamentais da Declaração de Princípios dos Institutos Liberais, abordar a percepção de Donald Stewart Jr. acerca da democracia, o que merece uma análise particular. Existe, a esse respeito, uma dupla abordagem do autor: uma abordagem pragmática e uma abordagem pessoal. Do ponto de vista pragmático, Donald, como liderança 
do Instituto Liberal, encampava, como agenda a ser acolhida por todos os institutos de mesma natureza e missão, a defesa da democracia representativa. Pessoalmente, porém, não deixava de externar, tal como outro importante ativista brasileiro do liberalismo, igualmente entusiasta das ideias de Hayek, Henry Maksoud (1929-2014), sua preferência por uma espécie de alternativa ou variante hayekiana a esse regime: a demarquia.

Na Declaração de Princípios, os Institutos Liberais concordavam em sustentar a democracia, definindo-a como "a liberdade para escolher as pessoas que exercerão as funções de governo e que, portanto, irão deter o comando do aparato de coerção e compulsão" (STEWART JR., 2019, p. 136). De forma mais detalhada, subscrevem que, para que se verifique verdadeira liberdade de escolha nesse campo,

é indispensável que haja eleições periódicas, que os indivíduos possam se organizar em torno de ideias e princípios que considerem mais adequados para a sociedade e que possam formar partidos políticos de qualquer natureza. Essa liberdade de escolha precisa estar protegida por salvaguardas, de forma a impedir que um partido político, eventualmente no poder, venha a utilizar o aparato de coerção para suprimi-la; uma eventual maioria política não pode ter o direito de suprimir eleições ou de impedir a formação e a atuação de partidos políticos. (STEWART JR., 2019, p. 136)

Apesar de a Declaração de Princípios datar de 1988, Donald Stewart Jr. e o Instituto Liberal tinham um compromisso estatutário, desde a fundação, em 1983, com o sistema democráticorepresentativo. O Brasil, à época, estava no ciclo final de um longo período de autoritarismo militar e se preparando para uma revisão de premissas, tanto políticas quanto jurídicas e econômicas. Vozes liberais, em especial a de Roberto Campos, se manifestavam com o propósito de garantir que houvesse uma transição política, mas que ela se fizesse acompanhar de uma revisão dos rumos dirigistas e intervencionistas da economia. Donald e o Instituto Liberal se somavam a esse esforço, por perseguir uma transição dupla.

Entretanto, pessoalmente, Donald Stewart Jr. acreditava que a separação de poderes tal como esboçada nos regimes políticos modernos não é suficiente. Para que ela fosse genuína e completa, seria necessário, na opinião dele,

que os legisladores não tivessem qualquer vinculação político-partidária. Só assim se poderia assegurar que as regras a serem respeitadas pela sociedade, as chamadas leis, fossem enunciadas com a indispensável tecnicidade e com o necessário distanciamento em relação à sua aplicação aos casos futuros. (STEWART JR., 2019, p. 121)

A proposta confessadamente reproduz o projeto demárquico de Hayek. O regime da demarquia diferiria do regime das contemporâneas democracias liberais porque separaria o Congresso atualmente existente, onde há uma representação dos eleitores através dos parlamentares com a função de debater e criticar o governo e disputar o poder, do Poder Legislativo propriamente dito. Os deputados e senadores como conhecidos atualmente passariam a não mais dispor do poder de propor e estabelecer leis, o que caberia exclusivamente a uma Assembleia Legislativa autônoma com o propósito de "elaborar as regras a partir de proposições de seus próprios membros, dos representantes do executivo, do judiciário ou dos 
partidos políticos" (STEWART JR., 2019, p. 121). Os membros desta Assembleia seriam eleitos anualmente para um mandato não-renovável de 15 anos e deveriam estar desvinculados de qualquer partido político, antes e depois do período em que ocupariam o cargo, para sempre.

Para Hayek e Donald Stewart Jr., o fato de representantes dos partidos serem eleitos com a função de elaborar as leis, que deveriam ser regras fundamentais de número restrito, faz com que essas leis sejam sempre pressionadas pelos interesses eleitorais. Os dois consideravam que, idealmente, qualquer esfera em que houvesse uma disputa por poder entre os partidos deveria pertencer ao Poder Executivo e estar direcionada exclusivamente para o exercício do governo ou a crítica às suas ações, nunca para a proposição e enunciado de leis. O Poder Legislativo deveria ser não-partidário, assim como o Judiciário.

Somente um liberal muito influenciado pela Escola Austríaca e com uma visão bastante ortodoxa do pensamento de Friedrich Hayek poderia adotar a tese da demarquia. Liberais brasileiros mais afastados da Escola Austríaca, como Antonio Paim, manifestaram explícito desagrado com essa linha de pensamento. Segundo Paim, a demarquia, "como apontaram Karl Popper e outras expressivas personalidades liberais, não tem muito a ver com o liberalismo" (PAIM, 2018, p. 348). Paim, ao avaliar o pensamento de Stewart, ressalta o reconhecimento, por parte do empresário, de que o alicerce para o comportamento econômico de uma comunidade política está mais nas suas instituições do que na religião e na moral e que, em consequência disso, Stewart procurou, através do Instituto Liberal, sugerir uma conformação institucional mais propícia ao sucesso e ao desenvolvimento que, em linhas gerais, está calcada em uma "declaração de direitos centrada na liberdade individual e na propriedade privada" (PAIM, 2018 , p. 348) e, por consequência, em premissas liberais - mas que delas se afastaria ao abraçar a demarquia.

Em toda a sua obra, Paim caracteriza os liberais brasileiros como herdeiros do pensamento de Silvestre Pinheiro Ferreira, que teorizou ser justamente a representação dos interesses a garantia do sucesso do sistema representativo. Essa teoria influenciou os liberais que construíram e mantiveram por décadas o Estado monárquico brasileiro.

Paim considera, contra Stewart, que,

na esfera política, o consenso é francamente antidemocrático. A esfera política consiste numa disputa de interesses que, para alcançar uma expressão possível de ser negociada, devem afunilar-se, sendo esta precisamente a missão do partido político. As eleições devem permitir a formação de maiorias capazes de implementar o programa vitorioso. De sorte que o mínimo que se pode dizer da "demarquia" é que nada tem a ver com a ideia liberal e muito menos com o governo representativo. Salvo este senão, a proposta de Donald Stewart Jr. pode ser integralmente subscrita. (PAIM, 2018, p. 349)

Ao contrário, no programa demárquico de que Stewart era entusiasta, a Assembleia Legislativa se encarregaria de determinar as condições mínimas de segurança e saúde de que os cidadãos deveriam gozar, bem como especificar a fonte dos recursos entre os impostos. Assim como Hayek e contrariando liberais e libertários mais radicais, como os objetivistas e os anarcocapitalistas, Donald Stewart Jr. reconhecia a possibilidade de o Estado, tendo em vista um nível mínimo de equilíbrio e ordem social, auxiliar diretamente pessoas que estivessem 
em condições de extrema vulnerabilidade, em vez de deixá-las na total dependência da ajuda privada. A parcela do Estado que determinaria esse auxílio, entretanto, não seria o governo, isto é, não seria o Poder Executivo, nem o Congresso, e sim os representantes teoricamente neutros do Poder Legislativo. Isso faria das políticas assistencialistas uma ação de Estado e não de governo.

O sistema por meio do qual esses benefícios seriam concedidos seria o sistema de vouchers, uma das principais bandeiras do economista liberal da Escola de Chicago Milton Friedman. Um ticket seria cedido a cada cidadão que tivesse necessidades, concedendo direito a determinado período de atendimento em escolas ou instituições de saúde. "Idêntico procedimento deveria ser adotado para qualquer outra condição mínima que se considere indispensável estender a todos os cidadãos pelo simples fato de pertencerem à mesma comunidade" (STEWART JR., 2019, p. 123), afirmou, estendendo a possibilidade a outros gêneros de necessidades extremas, que porventura as circunstâncias determinassem e justificando a concessão desses benefícios apelando a uma obrigação social que seria do interesse de todos os cidadãos.

“O essencial é que a concessão desses benefícios seja feita diretamente aos indivíduos, que escolherão, no mercado, quem melhor lhes pode conceder o produto ou serviço em questão" (STEWART JR., 2019, p. 123), pois, segundo Stewart, o Estado se encarregar diretamente da produção e oferta do serviço em vez de apenas facilitar o acesso a quem não tem condições financeiras é um mecanismo estatisticamente mais caro e ineficiente. A Assembleia Legislativa deveria, ao mesmo tempo em que determina a concessão desses programas assistencialistas, "igualmente indicar a fonte de recursos, ou seja, qual o imposto ou aumento de imposto cuja arrecadação proverá o governo com os recursos necessários à implementação desses benefícios" (STEWART JR., 2019, p. 123), demonstrando que esses recursos existem e que a determinação não seria demagógica e inviável.

Há com isso, no projeto hayekiano de Donald Stewart Jr., um esforço por moralizar a instância do Estado que configuraria as regras fundamentais a serem seguidas por todos os integrantes da comunidade política e os benefícios que seriam oferecidos aos mais pobres. Essas questões, que hoje estão no centro da maior parte dos debates e enfrentamentos políticos, ficariam de fora do universo da política partidária propriamente dita e seriam tratadas de forma pretensamente mais técnica.

\section{A Ação Humana no Centro do Pensamento de Donald Stewart Jr.}

A Escola Austríaca é uma corrente de pensamento econômico cuja origem é normalmente atribuída ao trabalho de Carl Menger (1840-1921), dando início a uma sequência de gerações que desenvolvem seus fundamentos e expressam concepções distintas. Sua pluralidade tornou-se um desafio, que não permaneceu livre de questionamentos e tensões, de resumir os postulados comuns a todos esses autores. Entretanto, considera-se que o esforço do austríaco Fritz Machlup (1902-1983) é um parâmetro de qualidade para sintetizar as características que os acompanham e permitem reconhecer sua filiação à escola. 
O primeiro desses aspectos seria o chamado individualismo metodológico, princípio que considera a necessidade de explicar os fenômenos econômicos a partir de atitudes individuais. Apenas a ação humana individual poderia ser utilizada como premissa para compreender os fatos e relações, porque os coletivos somente existem em decorrência da decisão e ação dos indivíduos.

Ao lado do individualismo metodológico, Machlup inclui o subjetivismo metodológico, princípio definido pela afirmação de que "temos de voltar para o julgamento e escolhas feitas por indivíduos, com base em todo o conhecimento que têm ou acreditam ter e quaisquer que sejam as expectativas que tenham" (MISES, 2017, p. 22).

Em terceiro lugar, vem o princípio dos gostos e preferências, segundo o qual o que determina os preços dos produtos nas relações econômicas não seria o trabalho despendido em sua elaboração ou qualquer outro fator concebível, mas as "valorações subjetivas de bens e serviços" (MISES, 2017, p. 22), inteiramente determinadas pelos consumidores.

O quarto princípio é o dos custos de oportunidade, segundo o qual "os custos com que os produtores e outros agentes econômicos calculam refletem as oportunidades alternativas que devem ser previstas" (MISES, 2017, p. 22). O quinto fundamento é o marginalismo, que prega que, "em todos os modelos econômicos, os valores, os custos, as receitas, a produtividade etc., são determinados pelo significado da última unidade adicionado ou subtraído do total" (MISES, 2017, p. 22-23). Por fim, o último princípio dita que a decisão de poupar recursos decorre das preferências temporais, mediante as quais o indivíduo decide se deve preferir um consumo imediato ou não e os investimentos "são feitos esperando um maior retorno, caso os processos de produção sejam mais moderados" (MISES, 2017, p. 23).

Não obstante não se trate de uma regra absoluta - o próprio Machlup reconhece que ninguém menos que o fundador da escola, Menger, não aceitava o sexto e último princípio -, essa lista reúne postulados que serão reconhecidos em significativa parcela dos defensores da lógica econômica da Escola Austríaca. Não há negar, porém, que os nomes mais famosos dessa corrente são os de Ludwig von Mises e Friedrich Hayek e o segundo foi aluno do primeiro. Partindo desse princípio, Machlup considera que existem dois princípios adicionais que o ramo dos discípulos de Mises defende e que não necessariamente são compartilhados pelos seus antecessores dentro da escola.

O primeiro desses princípios é a soberania do consumidor, cujos desejos, aspirações e inclinações deveriam ser os principais ditames das atividades econômicas, sem a influência das intervenções governamentais. O segundo é o individualismo político, que transcende o mero individualismo metodológico para atingir o patamar de uma verdadeira bandeira.

Os misesianos dirão que:

só quando os indivíduos tiverem uma plena liberdade econômica será possível assegurar a liberdade política e moral. Restrições à liberdade econômica levam, cedo ou tarde, a uma extensão das atividades coercitivas do Estado para o plano político, minando e, por fim, destruindo as liberdades individuais essenciais que as sociedades capitalistas foram capazes de alcançar no século XIX. (MISES, 2017, p. 24) 
Donald Stewart Jr. era evidentemente um austríaco de linhagem misesiana, especificamente um entusiasta de seu pupilo Hayek. Subscrevia, em consequência, absolutamente todos os oito princípios elencados por Fritz Machlup. Como eixo norteador desses oito princípios, mais do que isso, ele se dedicou a divulgar um dos conceitos mais centrais na obra de Mises: a Praxeologia.

Basicamente reproduzindo os conceitos exarados por Mises em sua obra magna, Ação Humana: um tratado de economia, em seu opúsculo O Que é o Liberalismo, dedicando um capítulo inteiro de seu trabalho apenas a esmiuçar esse tema, Stewart se tornou um pioneiro na divulgação, no Brasil, daquilo que o próprio Mises considerava sua grande contribuição metodológica: a subordinação da Economia a uma ciência maior, voltada a estudar a ação humana, cujo nome era justamente esse: Praxeologia.

Stewart reproduz a afirmação primordial da Praxeologia, segundo a qual toda ação humana, qualquer que seja, "visa a passar de um estado de menor satisfação para um estado de maior satisfação" (STEWART JR., 2019, p. 61) ou "substituir um estado de maior desconforto por um estado de menor desconforto" (STEWART JR., 2019, p. 62). Ao mesmo tempo, reafirmando o princípio do subjetivismo metodológico, ele também ressalta, com Mises, que a economia não está interessada em avaliar ou precisar os fins a que os indivíduos almejam, tão diversificados quanto os indivíduos, mas em estudar os meios através dos quais perseguem esses fins. Ele sintetiza: “O problema econômico decorre, basicamente, do fato de os meios serem escassos e os fins alternativos ilimitados. Ao utilizar um meio escasso para atingir um determinado fim, o homem renuncia a inúmeros outros fins que poderiam ser atingidos com aquele mesmo meio" (STEWART JR., 2019, p. 64).

Concordando explicitamente com o princípio do individualismo metodológico, Stewart ressalta que a escolha de objetivos e meios "é sempre individual e nunca coletiva. Os homens podem ter objetivos em comum e usar os mesmos meios para atingi-los, mas isso não configura uma decisão coletiva ou do coletivo" (STEWART JR., 2019, p. 64). Será sempre, em sua concepção, um conjunto de ações individuais que se unem com um propósito comum, mas tudo poderá ser sempre reduzido a ações individuais.

Apesar disso, Mises não nega a existência da sociedade; apenas a define, na espécie humana, como "ação concertada, cooperação" (MISES, 2010, p. 183), elegendo, conforme já enfatizado, a cooperação como um dos elementos centrais do liberalismo, ao contrário do que muitos críticos costumam alegar. Mises também define a sociedade como "consequência do comportamento propositado e consciente" (MISES, 2010, p. 183). É quase literalmente o mesmo que Donald Stewart Jr. dirá, ao conceituar que “sociedade é ação em concerto, é cooperação; é fruto do comportamento propositado do homem" (STEWART JR., 2019, p. 67).

O propósito central aqui, tanto de Mises, quanto de Stewart, reside em não tolerar a ideia de uma separação muito bem definida entre a sociedade e os indivíduos que a compõem, como se a sociedade e o coletivo tivessem vida própria. O tempo inteiro, para esses autores, tanto a comunidade política como um todo quanto os corpos intermédios da sociedade, isto é, as diversas esferas de associação entre os seres humanos, somente existem em dependência incessante da ação humana individual de cada integrante. 
Nesse sentido, um dos maiores acontecimentos de todos os tempos teria sido "o advento da cooperação social entre estranhos, de importância inexcedível para a humanidade" (STEWART JR., 2019, p. 69), que foi possível muito mais em função dos interesses de cada indivíduo do que por razões altruístas. Desenvolvendo-se essa cooperação, os indivíduos teriam percebido que seria necessário estabelecer regras para a convivência entre eles, as leis, e os Estados teriam surgido posteriormente a isso como mecanismos institucionais para garantir que essas regras fossem respeitadas. Para Donald, contudo, novamente ecoando Mises e Hayek, uma lei digna do nome deveria ser "de justa conduta aplicável a todos os casos futuros" (STEWART JR., 2019, p. 71). Significativa parcela daquilo que os parlamentos contemporâneos produzem sob o nome de leis seria apenas composta de "legislações, regulamentos, portarias e atos autoritários impostos sobre a sociedade" (STEWART JR., 2019, p. 71), problema que justamente Stewart preferiria tentar solucionar adotando a receita hayekiana da demarquia.

Um detalhe peculiar do pensamento de Stewart é sua afinidade com o direito consuetudinário inglês, segundo o qual "cabia aos juízes a função de "descobrir" as leis, isto é, de tornar explícitas, através da jurisprudência, as normas de conduta que, por serem habitualmente adotadas, deviam ser consideradas como o comportamento que se espera de uma pessoa" (STEWART, 2019, p. 72). A descoberta das leis significaria a identificação do que funciona e do que não funciona, porque as boas regras, na visão de Stewart, apenas o são por guardarem relação direta com os imperativos e condicionantes da realidade. Ele pontuaria que a imposição de leis que contrariem esses imperativos e condicionantes

só poderá ser feita pelo aumento da coerção. Na medida em que isso ocorra, a sociedade livre transforma-se em uma sociedade submetida a um poder autoritário, seja ele o monarca, o déspota, o ditador militar ou o representante de uma eventual maioria que controla um Estado todo poderoso. (STEWART JR., 2019, p. 73)

Uma vez estabelecidas as regras e configurado o Estado, há um ambiente em que se devem determinar prioridades e objetos a serem produzidos. O melhor meio de fazer essa determinação, para Stewart - mais uma vez, como para Mises, Hayek e praticamente todos os austríacos - é a cooperação social através das relações espontâneas de mercado e não o planejamento centralizado, feito por um mesmo corpo burocrático ou até por um indivíduo dotado de plenos poderes. O mercado é um mecanismo mais eficiente porque nenhum indivíduo é capaz de concentrar todas as informações necessárias à avaliação da produção e dos objetivos que ela visa a atender, o que configura, em Donald Stewart Jr., uma perfeita reprodução da abordagem do problema do conhecimento, tal como tradicionalmente exposto por Hayek.

Com efeito, Stewart também define o mercado como "um processo de transmissão de informações" (STEWART JR., 2019, p. 73), cuja materialização se dá sob a forma dos preços. A deliberação dos indivíduos na sociedade quanto a consumir ou não um determinado produto é, na prática, uma informação transmitida ao mercado, que impacta nas decisões dos vendedores e dos produtores. Isso explica o grande problema do intervencionismo, visto como uma ameaça à liberdade e à vida social pelos austríacos, especialmente os integrantes daquilo que Machlup chama de ramo misesiano. 
Stewart dirá que as mais diversas categorias de intervenções estatais no mercado "deformam os preços e, portanto, deformam as informações a serem processadas pelo mercado. Quanto maior a intervenção, maior a deformação dos preços e maior a desinformação daí decorrente" (STEWART JR., 2019, p. 74). Essas intervenções podem estimular uma produção decorrente de um subsídio que, na realidade, provoca uma demanda fantasiosa, sem sustentação, ou podem desestimular a confecção de produtos que efetivamente interessariam aos consumidores, especialmente a médio e longo prazo.

Tendo conhecido na prática a realidade do mundo empresarial, Donald Stewart Jr. reserva espaço relevante para refletir sobre a função do empresário, discussão em que faz uso das explanações de outro economista da Escola Austríaca, Israel Kirzner. Para ele, o empresário é um personagem essencial não apenas por exercer o papel de perseguir mecanismos mais ágeis e eficientes para a produção, mas principalmente porque tem a função de inovar e descobrir o que os demais indivíduos não percebem:

A atividade empresarial pura é um processo de descobertas; o papel do empresário puro é estar alerta para perceber oportunidades que até então passavam despercebidas. Descobrir oportunidades inexploradas exige um estado de alerta (alertness). A economização e a otimização, por si mesmas, não são capazes de gerar essa descoberta. A atividade economizadora só pode "deduzir" melhoramentos que estão implícitos no conhecimento existente, mas não lhe é possível "descobrir" porque, por definição, a descoberta não está implícita no conhecimento existente. O que gera oportunidades de lucro empresarial puro é a imperfeição do conhecimento existente entre os participantes no mercado. O processo gerador de lucro é, portanto, um processo de correção da ignorância dos participantes no mercado. É um processo de remoção da ignorância. (...) A descoberta de uma oportunidade de lucro representa a descoberta de alguma coisa obtenível em troca de nada; algo obtido depois de pagos todos os custos. Ou seja, o lucro puro tem custo zero. O lucro puro é gerado ex-nihil; é criado a partir do nada. $\mathrm{O}$ valor assim gerado corresponde a uma verdadeira criação. (STEWART JR., 2019, p. 81)

O empresário por excelência seria, para Donald Stewart, alguém que faz descobertas até de possibilidades que sequer eram cogitadas anteriormente, o que faz de seu trabalho uma verdadeira criação. Ainda que majoritariamente ou totalmente não seja um labor braçal, a atividade do empresário é considerada peça central da engrenagem do mercado e merecedora da devida remuneração, isto é, do lucro advindo de sua descoberta e iniciativa. O combate à figura do empresário e à sua atividade significa a luta por impedir inovações e "a remoção de nossa ignorância e, portanto, a correção dos erros que cometemos em virtude de nossa ignorância" (STEWART JR., 2019, p. 83).

A ação humana do empresário, identificando problemas e possibilidades, a partir de uma difícil avaliação das informações fornecidas pelo mercado, seguindo a regra de buscar o deslocamento de uma situação de maior desconforto para uma situação de maior conforto, faculta a que as necessidades dos consumidores sejam atendidas - mesmo necessidades que eles sequer sabiam que tinham ou que poderiam ser satisfeitas. Para que esse processo se verifique, é preciso, como advoga o liberalismo de Stewart, que haja liberdade de entrada no mercado, o que inevitavelmente redundará em competição. 
Para Donald Stewart Jr., a competição inevitável traz benefícios para o conjunto da sociedade, especialmente para os consumidores, quanto mais livre e abrangente for. Ele favorece a liberdade de competição de empresários dentro de um mesmo território nacional, entre empresários de diferentes países e mesmo em todo o planeta, caso em que "seus efeitos serão o máximo que o homem pode almejar nas condições vigentes de conhecimento tecnológico e de disponibilidade de capital" (STEWART JR., 2019, p. 84). Por isso mesmo, para o autor, uma das funções essenciais do Estado "é assegurar a liberdade de entrada no mercado, de forma a possibilitar a maior competição possível" (STEWART JR., 2019, p. 84). Eis porque o irritavam tanto, no Estado brasileiro, as promoções de artifícios como "a reserva de mercado, o protecionismo, a carta patente, privando assim os indivíduos, os consumidores, dos benefícios que a competição ensejaria" (STEWART JR., 2019, p. 84).

Apesar das experiências desagradáveis envolvidas na competição, como o fechamento de empresas e a demissão de seus empregados, Stewart afirma que é inconcebível uma organização social que não envolva qualquer gênero de competição em sua dinâmica interna, a menos que o líder supremo de um regime totalitário "não seja de forma alguma influenciado pela ambição ou pelo desejo de seus subordinados. Os indivíduos seriam indiferentes ao seu destino. Se as pessoas agissem dessa forma, já não seriam seres humanos" (STEWART JR., 2019, p. 86).

Por fim, alguns autores, inclusive autodeclarados liberais, defendem a busca do que chamam de igualdade de oportunidades. O liberalismo de Stewart rejeita o conceito. Para ele, a começar pela desigualdade fisiológica existente entre as pessoas, por natureza, é impossível cogitar uma equiparação plena entre as possibilidades de todas as pessoas no mercado e nos diversos setores da vida. Contudo, ao citar o argumento dos que afirmam que ao menos todos deveriam ter a oportunidade de acesso à saúde e à educação, Stewart consente em que "isso é extremamente desejável, não por configurar uma maior igualdade de oportunidades, mas por aumentar a competição" (STEWART JR., 2019, p. 91).

Em sua concepção, a melhoria da qualidade de vida e da mão-de-obra disponível para a produção no mercado facilita, inclusive, o respeito às regras, que é fundamental para a manutenção de uma sociedade livre. A multiplicação de pessoas sem acesso ao mínimo necessário para subsistência e dignidade de vida é considerada um risco para toda a ordem social, mesmo que seja uma ordem social pautada pelo liberalismo. Por isso, de alguma forma, Stewart entende que é preciso garantir esse mínimo. Qual seria esse mínimo e como concedêlo? Ele detalhou seu raciocínio a respeito da seguinte forma:

Para simplificar a discussão e colocá-la nos seus devidos termos, sugiro que seja concedido aos mais carentes tudo o que desejam os mais veementes defensores da distribuição de renda via intervenção do Estado, desde que sejam observados dois princípios básicos: 1 - que existam os recursos; senão a distribuição é uma farsa, mera demagogia e não pode ser levada a sério;

2 - que os recursos sejam entregues diretamente aos indivíduos, que deveriam ser livres para escolher, por exemplo, a escola em que vão colocar seus filhos ou o seguro de saúde que os atenderá em caso de necessidade.

É óbvio que o mínimo a ser assegurado a cada um não poderá ser o mesmo na Suécia ou no Gabão, tendo em vista a diferença de capital acumulado num caso e no outro. No caso 
brasileiro, o nível de riqueza já atingido pelo país é, seguramente, mais do que suficiente para assegurar a todos um razoável mínimo de educação e de saúde. Os recursos para isso existem e a comunidade os paga sob a forma de impostos. (...)

O problema se resolveria facilmente - a sugestão é de Milton Friedman - se fosse dado a cada aluno em idade escolar, cujos pais não pudessem arcar com a sua educação, um cupom, ou seja, um ticket (como esses usados para restaurante) que desse direito a um período escolar. Caberia ao aluno, por meio de seus responsáveis, escolher a escola que deseja frequentar e ter, portanto, acesso à mesma educação que é ministrada aos filhos dos que têm melhor situação econômica. Isso obrigaria as escolas e os professores, os produtores, a competirem, procurando oferecer a melhor qualidade de ensino possível aos alunos, os consumidores. (STEWART JR., 2019, p. 92-93)

Conforme já abordado anteriormente, o mesmo recurso seria aplicado à área da saúde, substituindo-se apenas as escolas por hospitais. A defesa de Donald Stewart Jr. de que o liberalismo não signifique abdicar dessa possibilidade assistencialista mínima, embora encontre acolhimento também dentro da Escola Austríaca, especialmente pelo próprio Hayek, ecoa a clara preocupação do autor brasileiro com a ideia de ordem. Com efeito, um ingrediente importante de seu pensamento, compartilhado com o de seu amigo e parceiro Og Leme, é o de que o que se persegue é uma ordem liberal, sem a qual o liberalismo não subsistiria.

Donald expressa francamente que "qualquer ordem é melhor do que o caos" (STEWART JR., 2019, p. 106). Contudo, "algumas regras produzem melhores resultados do que outras" (STEWART JR., 2019, p. 106). Na abordagem desse problema, assim como recorreu ao economista da Escola de Chicago Milton Friedman para defender a política da concessão dos tickets, chamados vouchers, Donald Stewart Jr. também recorre a um economista externo à Escola Austríaca, um dos fundadores da nova economia institucional, Douglas North (1920-2015). Com base em North, Stewart advoga que as instituições de uma sociedade, definidas como sendo "o conjunto compreendido pelas regras formais, pelas limitações informais (normas de comportamento, convenções e códigos de conduta auto-impostos) e pelos mecanismos responsáveis pela eficácia da aplicação dessas normas" (STEWART JR., 2019, p. 106), são mais importantes para definir o desempenho econômico do que a qualidade dos atores sociais.

Os incentivos oferecidos pela configuração institucional de uma sociedade, dentro dessa definição, são decisivos para os resultados que serão obtidos. Nesse sentido, o predomínio da ideologia do intervencionismo, problema que já se viu anteriormente ser marcante nas preocupações de Donald Stewart Jr., dentro do contexto do que outros autores liberais, empregando a matriz weberiana, chamariam de patrimonialismo, é um grave problema para a configuração institucional da sociedade brasileira.

Donald pontua que se "as instituições fizerem com que os mais bem-sucedidos sejam os que obtenham os favores do rei, do Estado, ou os que praticam a pirataria, os indivíduos e as organizações dedicarão o seu melhor esforço para obter privilégios ou para serem melhores piratas" (STEWART JR., 2019, p. 106). A proteção a esses favorecidos pelo Estado, além disso, tem por consequência, na outra extremidade das relações econômicas, o prejuízo dos consumidores, privados dos benefícios de uma autêntica competição em um regime de liberdade de entrada no mercado. 
Aqui, Donald Stewart Jr. traz outra referência intelectual importante em seu pensamento, que ele mais de uma vez citou como inspiração pessoal: o filósofo britânico David Hume (17111776), ícone do empirismo e do iluminismo escocês. Da filosofia humeana, Stewart extraiu que há três fatores a serem observados para que uma nação se desenvolva: "1) o direito de propriedade; 2) a transferência por consentimento; 3) o cumprimento dos compromissos assumidos" (STEWART JR., 2019, p. 108). Ressaltou ainda o seguinte pensamento do filósofo britânico: "A principal virtude de uma sociedade politicamente organizada consiste no estabelecimento de leis que imponham restrições ao comportamento de seus membros - as quais eles não estariam dispostos a aceitar voluntariamente" (HUME, 1948, p. 69-90).

Na concepção de Stewart, não houve nenhum acréscimo à visão de Hume nos últimos séculos, continuando a ser esse o objetivo: uma sociedade que combine a eleição democrática com a economia de mercado e o respeito ao direito de propriedade. A ação humana individual é o motor de todas as realizações e, consequentemente, da economia, mas ela será endereçada ao sucesso se os estímulos do arranjo institucional e da ordem estabelecida forem os estímulos corretos.

\section{Conclusão}

Os principais trabalhos teóricos produzidos por Donald Stewart Jr., entre opúsculos e palestras, tinham por objetivo imediato a propaganda. Ele não tinha o propósito de inaugurar conceitos, mas de difundir, em meio maciçamente estranho às suas teses, alguns dos principais autores estrangeiros do liberalismo. Não se pode identificar, na literatura brasileira, antes de Donald, um trabalho como o dele, de conformações didáticas e voltado ao público mais amplo possível com a finalidade de difundir as teses liberais.

Entretanto, não é possível deixar de registrar menções a seu papel mais importante, que foi institucional e aglutinador. Foi através da fundação e manutenção do Instituto Liberal que Donald deixou seu maior legado para o pensamento político brasileiro. Antes de 1983, havia instituições como o Instituto Brasileiro de Filosofia, fundado em São Paulo, em 1949, pelo jurista e filósofo Miguel Reale (1910-2006). ${ }^{1}$ Esse instituto estudava os princípios liberais; entretanto, a divulgação exclusiva do liberalismo e suas diversas tendências internas passava longe de ser a preocupação central da instituição, com finalidades muito mais abrangentes.

Sendo assim, o Instituto Liberal foi uma realização inédita no país, inspirando-se em modelos de centros de pensamento ou think tanks já existentes em outros lugares do mundo e buscando estabelecer relações de parceria com esses similares internacionais. O impacto dessa instituição para o enriquecimento e a articulação dos estudiosos e analistas do pensamento liberal pode ser avaliado a partir do registro de alguns dos nomes que por ela passaram.

Inúmeros pensadores então já em atividade, de José Guilherme Merquior a Roberto Campos, passando pelo embaixador José Osvaldo de Meira Penna (1917-2017), Alberto Oliva, ${ }^{1}$ O professor Ricardo Vélez Rodríguez oferece oportunas informações sobre o histórico desta instituição no seguinte
endereço virtual. Disponível em: http://www.ecsbdefesa.com.br/defesa/fts/60IBF.pdf. Acesso em: 10 mar 2020. 
Mário Guerreiro, Ubiratan Borges de Macedo (1937-2007) e Ricardo Vélez-Rodríguez, encontraram no Instituto Liberal um espaço de confluência e difusão organizada de ideias e conhecimento. Para além disso, pensadores de uma geração mais jovem, também dedicados a difundir o liberalismo, aí encontraram, ao menos em parte significativa, o alicerce de sua formação intelectual, alguns deles estando ainda em plena atividade, a exemplo do historiador e editor Alex Catharino, discípulo direto de Ubiratan Borges de Macedo e Og Leme, e o economista Rodrigo Constantino, responsável, a partir de 2013, por presidir o Conselho Deliberativo do Instituto Liberal.

Esse trabalho é reconhecido por ter influenciado a criação de outras instituições ao redor do país, além de grupos e movimentos organizados que sucederam ao Instituto Liberal no esforço de estabelecer uma rede de relacionamentos. O Instituto Mises Brasil, o Instituto de Estudos Empresariais, o Students for Liberty Brasil, o Partido Novo, o Movimento Brasil Livre, entre outros grupos bastante heterogêneos que modificaram a paisagem intelectual, política e ideológica brasileira, se tornaram possíveis, em grande medida, depois que a bibliografia produzida pelo Instituto Liberal atingiu reverberação nos meios virtuais.

O enfoque deste trabalho, porém, foi demonstrar especificamente o relacionamento da obra de Donald Stewart Jr. com a Escola Austríaca de Economia. Partindo de uma abordagem histórica, que situa a originalidade de sua atuação no contexto do liberalismo brasileiro desde suas origens, ficou demonstrado que o empresário pretendeu preencher a lacuna que Antonio Paim havia apontado como a mais grave nas últimas gerações de liberais brasileiros, principalmente as posteriores à ditadura do Estado Novo: a desconexão com o movimento liberal internacional e com as bibliografias produzidas no exterior. Em grande medida, do ponto de vista de Stewart, transpor essa lacuna significou trazer ao conhecimento mais amplo dos brasileiros os princípios dos economistas da Escola Austríaca.

Travando o necessário contato com uma sucinta exposição biográfica de Donald Stewart Jr., passou-se em seguida a destrinchar de que forma ele construiu sua abordagem pessoal do conceito de liberalismo, sua concepção da democracia e da organização social. O propósito foi, ao mesmo tempo em que se exibe um panorama das concepções do autor acerca da organização social e da plataforma político-teórica que os liberais deveriam defender, atestar que suas influências mais constantes são exatamente as de Friedrich Hayek e Ludwig von Mises, com citações a Israel Kirzner e plena obediência às características dos adeptos da Escola Austríaca elencadas por Fritz Machlup. Sua recorrência a autores externos a esta escola, como Milton Friedman e Douglas North, em nenhum momento o afasta das consequências inerentes à sua franca adesão à referida escola econômica.

Espera-se que, tanto no Brasil, quanto entre qualquer público estrangeiro interessado no fenômeno do alastramento das ideias liberais e do pensamento austríaco em território brasileiro, trabalhos como este estimulem que as contribuições originais e fundamentais de Donald Stewart Jr. sejam progressivamente reconhecidas, sem o que um significativo rombo permaneça na compreensão da realidade contemporânea. 


\section{Referências}

MISES, Ludwig von. Liberalismo. Rio de Janeiro: José Olympio; Instituto Liberal, 1987.

MISES, Ludwig von. Ação Humana. São Paulo: Instituto Ludwig von Mises Brasil, 2010.

MISES, Ludwig von. O contexto histórico da Escola Austríaca de Economia. São Paulo: LVM, 2017.

HUME, David. Moral and Political Philosophy. New York: Hafner Publishing Company, 1948.

PAIM, Antonio. História do liberalismo brasileiro. São Paulo: LVM, 2018.

RODRÍGUEZ, Ricardo Vélez. Os sessenta anos do Instituto Brasileiro de Filosofia. Disponível em: http:// www.ecsbdefesa.com.br/defesa/fts/60IBF.pdf. Acesso em: 07 mai 2020.

STEWART JR., Donald. O que é o liberalismo. São Paulo: LVM, 2019.

XAVIER, Dennys Garcia (org.). F. A. Hayek e a ingenuidade da mente socialista. São Paulo: LVM, 2019.

RECEBIDO: 20 DE JUNHO DE 2020. APROVADO: 15 DE OUTUBRO DE 2020. 